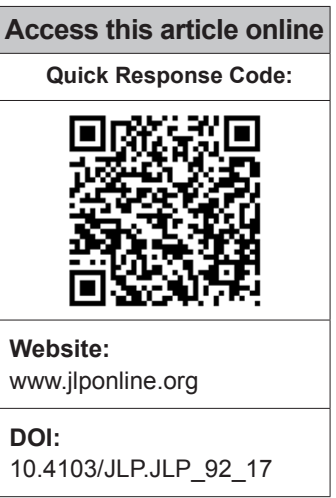

DOI:

/JLP.JLP 92
Departments of Microbiology and ${ }^{1}$ Surgery, Government Medical College, Haldwani, Uttarakhand, India

Address for correspondence:

Dr. Vinita Rawat, Department of Microbiology, Government Medical College, Haldwani, Uttarakhand, India. E-mail: drvinitarawat31@ rediffmail.com

Submission: 21-05-2017 Accepted: 03-08-2017

\section{Vancomycin, linezolid and daptomycin susceptibility pattern among clinical isolates of methicillin-resistant Staphylococcus aureus (MRSA) from Sub- Himalyan Center}

\author{
Afzal Husain, Vinita Rawat, Umesh, Mukesh Kumar, Pankaj Kumar Verma1
}

\begin{abstract}
:
INTRODUCTION: The efficacy of vancomycin, drug of choice for methicillin-resistant Staphylococcus aureus (MRSA), has become questionable due to the emergence of MRSA isolates with reduced susceptibility. The present study was conducted to determine the vancomycin, linezolid, and daptomycin susceptibility pattern in clinical isolates of MRSA and to observe minimum inhibitory concentration (MIC) creep over 2 years if any.
\end{abstract}

MATERIALS AND METHODS: MIC of vancomycin, linezolid, and daptomycin were determined by E-test in 198 MRSA isolates and their MIC 50, MIC 90, and geometric mean MIC were calculated.

RESULTS: While all isolates were sensitive to vancomycin, linezolid, and daptomycin, MIC 90 of vancomycin increased from $1.5 \mu \mathrm{g} / \mathrm{ml}$ in 2015 to $2 \mu \mathrm{g} / \mathrm{ml}$ in 2016. The percentage of isolates with vancomycin MIC >2 $\mu \mathrm{g} / \mathrm{ml}$ doubled in $2016(12.9 \%)$ as compared to $2015(6.1 \%)$. MIC 90 for linezolid remained steady as $3 \mu \mathrm{g} / \mathrm{ml}$, but geometric mean MIC increased from $2.20 \mu \mathrm{g} / \mathrm{ml}$ in 2015 to $2.29 \mu \mathrm{g} / \mathrm{ml}$ in 2016 , and more than $40 \%$ isolates showed MIC $3 \mu \mathrm{g} / \mathrm{ml}$. MIC 90 and geometric mean MIC of daptomycin decreased from $0.75 \mu \mathrm{g} / \mathrm{ml}$ to $0.5 \mu \mathrm{g} / \mathrm{ml}$ and $0.50 \mu \mathrm{g} / \mathrm{ml}$ to $0.36 \mu \mathrm{g} / \mathrm{ml} \mathrm{in}$ 2015 and 2016, respectively.

CONCLUSION: MIC creep was observed with vancomycin. Although linezolid MIC was within the susceptible zone, more than $40 \%$ strains showing MIC $3 \mu \mathrm{g} / \mathrm{ml}$ may herald the future development of either resistant or heteroresistant. Daptomycin showed good sensitivity against MRSA isolates. Therefore, it could be considered as an alternative agent for the treatment of infections caused by MRSA. However, it should be reserved where this class has a clear therapeutic advantage over other anti-MRSA drugs.

Key words:

Daptomycin, linezolid, methicillin-resistant Staphylococcus aureus, vancomycin creep

\section{Introduction}

Tancomycin has been the cornerstone in the treatment of patients with serious methicillin-resistant Staphylococcus aureus (MRSA) infections. Increased use of vancomycin has resulted in the emergence of MRSA with reduced susceptibility to vancomycin. ${ }^{[1-3]}$ Emergence of vancomycin intermediate or resistant

This is an open access article distributed under the terms of the Creative Commons Attribution-NonCommercial-ShareAlike 3.0 License, which allows others to remix, tweak, and build upon the work non-commercially, as long as the author is credited and the new creations are licensed under the identical terms.

For reprints contact: reprints@medknow.com
S. aureus has created the need for other anti-MRSA antibiotics. Many alternatives for treatment of MRSA infection including linezolid and daptomycin are currently approved by Food and Drug Administration. However, the emergence of resistance to linezolid and daptomycin in MRSA isolates has been recently reported ${ }^{[4,5]}$ In the present study, we determined vancomycin,

How to cite this article: Husain $A$, Rawat $V$, Umesh, Kumar M, Verma PK. Vancomycin, linezolid and daptomycin susceptibility pattern among clinical isolates of methicillin-resistant Staphylococcus aureus (MRSA) from Sub- Himalyan Center. J Lab Physicians 2018;10:145-8. 
linezolid, and daptomycin susceptibility pattern among clinical isolates of MRSA in a tertiary care center, Kumaon Region.

\section{Materials and Methods}

MRSA obtained from various clinical samples from July 2014 to June 2016 were prospectively collected. Only one isolate was selected from each patient. In total, 198 isolates were selected. All isolates were identified as $S$. aureus by using standard tests. ${ }^{[6]}$ Methicillin resistance was identified by cefoxitin disc according to Clinical and Laboratory Standards Institute (CLSI) guidelines. ${ }^{[7]}$ Minimum inhibitory concentration (MICs) of MRSA isolates to 3 antibiotics including vancomycin, linezolid, and daptomycin were determined by E-strip (Hi Media Mumbai, India) according to manufacturer's instruction. For disc diffusion, Quality control strains of S. aureus ATCC 25923 (Hi Media Mumbai, India) and for MIC, Quality control strains of S. aureus ATCC 29213 (Hi Media Mumbai, India) were used with every set of test. MIC 50, MIC 90, and geometric mean MIC for vancomycin, linezolid, and daptomycin were calculated in the fiscal year 2015 and 2016.

\section{Results}

A total number of MRSA isolates tested in the fiscal year 2015 and 2016 were 82 and 116, respectively. Source of MRSA isolation was 187 (94.5\%) from pus, 7 (3.5\%) from blood, and 4 (2\%) from body fluids, respectively. MIC 50, MIC 90, and geometric mean MIC for all three antibiotics, namely, vancomycin, linezolid, and daptomycin in fiscal years 2015 and 2016 are depicted in Table 1. MIC distribution in 2015 and 2016 is presented in respectively.

\section{Discussion}

MRSA is one of the leading pathogens for hospital- and community-acquired infections. In the present study, resistance to methicillin was seen in 30.7\% (198/644) of

Table 1: Minimum inhibitory concentration 50, minimum inhibitory concentration 90 , and geometric mean minimum inhibitory concentration of vancomycin, daptomycin, and linezolid in methicillin-resistant Staphylococcus aureus isolates

\begin{tabular}{lccccccc}
\hline Antibiotics & \multicolumn{3}{c}{2015} & \multicolumn{3}{c}{2016} \\
\cline { 2 - 3 } \cline { 6 - 7 } & MIC 50 & MIC 90 & $\begin{array}{c}\text { Geometric } \\
\text { mean }\end{array}$ & MIC 50 & MIC 90 & $\begin{array}{c}\text { Geometric } \\
\text { mean }\end{array}$ \\
\hline $\begin{array}{l}\text { Vancomycin } \\
(\mu \mathrm{g} / \mathrm{ml})\end{array}$ & 1.5 & 1.5 & 1.36 & 1.5 & 2 & 1.42 \\
$\begin{array}{l}\text { Linezolid } \\
(\mu \mathrm{g} / \mathrm{ml})\end{array}$ & 2 & 3 & 2.20 & 2 & 3 & 2.29 \\
$\begin{array}{l}\text { Daptomycin } \\
(\mu \mathrm{g} / \mathrm{ml})\end{array}$ & 0.5 & 0.75 & 0.50 & 0.38 & 0.50 & 0.36 \\
\hline
\end{tabular}

MIC = Minimum inhibitory concentration total S. aureus isolates, which is in concordance with other studies conducted in India. ${ }^{[8,9]}$ For decades, vancomycin was the mainstay in the treatment of infections caused by MRSA. However, recently, large number of literature has populated with vancomycin creep,,$^{[1-3]}$ where treatment failure has been observed with increased MIC of vancomycin within susceptible zone. CLSI has reduced the vancomycin susceptible breakpoint for S. aureus from $4 \mu \mathrm{g} / \mathrm{ml}$ to $2 \mu \mathrm{g} / \mathrm{ml}$ in 2006 .

The studies reporting vancomycin MIC creep have shown conflicting results. ${ }^{[1-3,10,11]}$ There are reports of increased MIC over the time, ${ }^{[1-3]}$ but other studies differ with these results. ${ }^{[10,11]}$ Variation in MIC results may perhaps be due to use of different methodologies and guidelines. A large multicenter surveillance studies such as SENTRY have not reported changes in vancomycin susceptibilities over time. ${ }^{[11]}$ The possible explanation for this observation ${ }^{[11]}$ may be that due to pooling of the data from multiple sites could conceal trends that may have existed within an individual institution(s). This highlights the importance of local surveillance of MICs, which would guide clinician in their empiric antibiotic selection in their local area.

In the present study, all MRSA were sensitive to vancomycin like other studies from India. ${ }^{[1,12]}$ The percentage of isolates with vancomycin MIC $>2 \mu \mathrm{g} / \mathrm{ml}$ doubled in 2016 (12.9\%) as compared to 2015 (6.1\%), and 3 isolates showed MIC of $3 \mu \mathrm{g} / \mathrm{ml}$ in the year 2016, suggesting the phenomenon of vancomycin MIC creep [Table 1 and Figures 1, 2]. Due to resource constrain, molecular typing on isolates exhibiting vancomycin creep could not be performed which would have reflected light whether isolates showing vancomycin MIC creep are associated with particular clone.

Daptomycin is cyclic polypeptide semisynthetic antimicrobial agent with activity against broad range of Gram-positive bacteria including MRSA and vancomycin-resistant $S$. aureus. ${ }^{[5]}$ As per CLSI guidelines, ${ }^{[7]}$ susceptibility breakpoint of daptomycin is considered as $\leq 1 \mu \mathrm{g} / \mathrm{ml}$ for Staphylococcus. There is a paucity of literature in daptomycin susceptibility on MRSA from India. Recently, a study from South India ${ }^{[1]}$ documented the MIC range of daptomycin from $0.0064 \mu \mathrm{g} / \mathrm{ml}$ to $1.5 \mu \mathrm{g} / \mathrm{ml}$ among MRSA isolates. Reduced susceptibility to vancomycin has been reported to be associated with reduced susceptibility to daptomycin..$^{[11,13]}$ In the present study, MIC range of daptomycin was $0.19-1 \mu \mathrm{g} / \mathrm{ml}$. MIC 90 and geometric mean MIC of daptomycin decreased from $0.75-0.5 \mu \mathrm{g} / \mathrm{ml}$ to $0.50-0.36 \mu \mathrm{g} / \mathrm{ml}$ in 2015 and 2016, respectively, despite vancomycin MIC creep. Few other studies ${ }^{[1,14]}$ have also observed similar trend of decreased MIC of daptomycin with an increase in vancomycin MIC. 


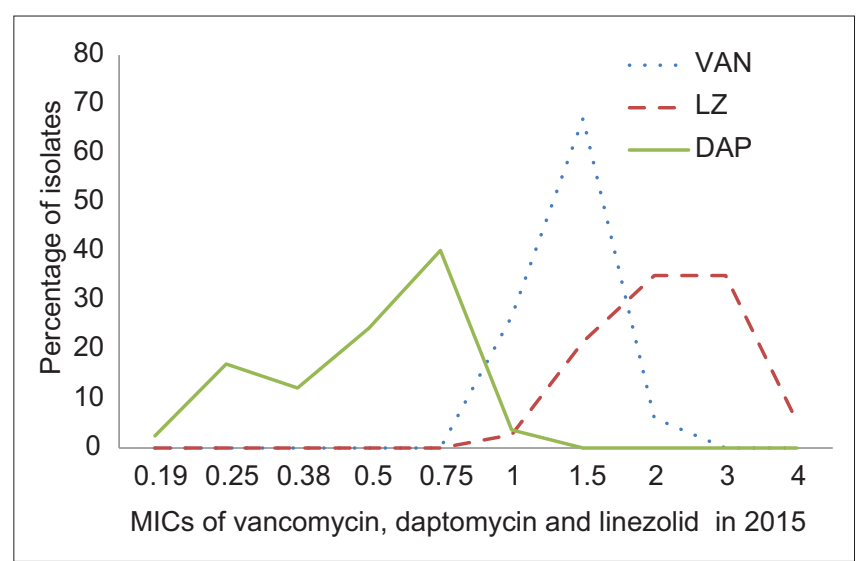

Figure 1: Minimum inhibitory concentrations of vancomycin, daptomycin, and linezolid in 2015

Linezolid is usually bacteriostatic against staphylococci and enterococci. Due to ease of oral administration, it is frequently used in community and hospital setting. Being a synthetic drug, the probability of naturally occurring resistant mechanism is very low. ${ }^{[15]}$

In the present study, all the MRSA isolates were sensitive to linezolid. Similar findings with no resistance against linezolid have been documented in many others studies. ${ }^{[12,16]}$ However, recently, cfr gene carrying MRSA and resistance due to mutation in $23 \mathrm{~S}$ rRNA has been reported from India. ${ }^{[4,15]} \mathrm{Cfr}$ gene has great potential of dissemination due to its association with mobile segment. ${ }^{[4]}$ In the present study, MIC 90 for linezolid remained steady as $3 \mu \mathrm{g} / \mathrm{ml}$, but geometric mean MIC increased from $2.20 \mu \mathrm{g} / \mathrm{ml}$ in 2015 to $2.29 \mu \mathrm{g} / \mathrm{ml}$ in 2016 . Hence, for close scrutiny, MICs should not only be measured by percentile susceptible markers but also by geometric mean statistics.

\section{Conclusion}

MIC creep was notably observed with vancomycin. Although linezolid MIC was within the susceptible zone, more than $40 \%$ strains showing MIC $>3 \mu \mathrm{g} / \mathrm{ml}$ may herald the future development of either resistant or heteroresistant. Daptomycin showed good sensitivity against MRSA isolates and can be used as alternative agents for the treatment of infections caused by MRSA in our setup. However, it should be reserved where this class has clear therapeutic advantage over other anti-MRSA drugs.

\section{Limitations}

We did not have data on antibiotic use in our hospital that would have clarified the relationship between antibiotic use and changes in MIC pattern. We could not explore the impact of vancomycin MIC creep on clinical outcome. Molecular typing on isolates exhibiting

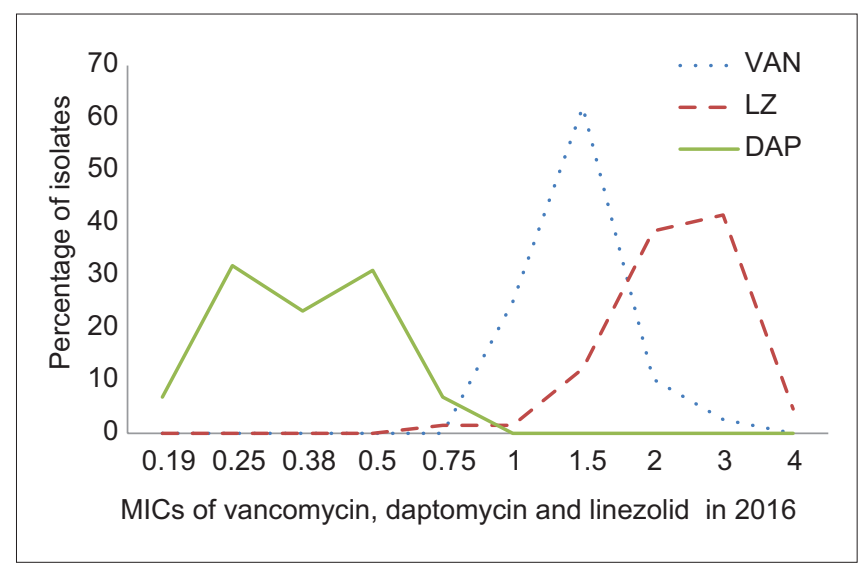

Figure 2: Minimum inhibitory concentrations of vancomycin, daptomycin, and linezolid in 2016

vancomycin creep could not be performed which would have reflected light on spread of particular clone with higher vancomycin creep.

\section{Financial support and sponsorship}

Nil.

\section{Conflicts of interest}

There are no conflicts of interest.

\section{References}

1. Niveditha N, Sujatha S. Worrisome trends in rising minimum inhibitory concentration values of antibiotics against methicillin resistant Staphylococcus aureus - Insights from a tertiary care center, South India. Braz J Infect Dis 2015;19:585-9.

2. Dhand A, Sakoulas G. Reduced vancomycin susceptibility among clinical Staphylococcus aureus isolates ('the MIC creep'): Implications for therapy. F1000 Med Rep 2012;4:4.

3. Chang W, Xiaoling M, Gao P, Lv X, Lu H, Chen F. Vancomycin MIC creep in methicillin-resistant Staphylococcus aureus (MRSA) isolates from 2006 to 2010 in a hospital in China. Indian J Med Microbiol 2015;33:262-6.

4. Basireddy S, Singh M, Ali S, Kabra V. CFR gene mediated linezolid resistance in staphylococcal isolates. Int J Pharm Bio Sci 2014;5:139-9.

5. Dortet L, Anguel N, Fortineau N, Richard C, Nordmann P. In vivo acquired daptomycin resistance during treatment of methicillin-resistant Staphylococcus aureus endocarditis. Int J Infect Dis 2013;17:e1076-7.

6. Winn WC, Allen SD, Allen S, Janda WM, Koneman EW, Schrekenberger PC, et al. Gram positive Cocci, Part 1: In Staphylococci and related Gram positive cocci. Koneman Color Atlas and Textbook of Diagnostic Microbiology. 6th ed. Philadelphia; Lippincott William and Wilkins: 2006. p. 624-73.

7. Clinical and Laboratory Standards Institute. Performance Standards for Antimicrobial Susceptibility Testing. 26 $6^{\text {th }}$ Informational Supplement. (M100-S26). Wayne, PA, USA: Clinical and Laboratory Standards Institute; 2014.

8. Durmaz B, Durmaz R, Sahin K. Methicillin-resistance among Turkish isolates of Staphylococcus aureus strains from nosocomial and community infections and their resistance patterns using various antimicrobial agents. J Hosp Infect 1997;37:325-9.

9. Debnath A, Chikkaswamy BK. Antibiogram and susceptibility pattern of methicillin resistant Staphylococcus aureus collected 
from various clinical samples in Bengaluru. Asian J Pharm Clin Res 2015;8:260-4.

10. Lu C, Guo Y, Wang S, Wang Z, Chen L, Lv J, et al. Decreased vancomycin MICs among methicillin-resistant Staphylococcus aureus clinical isolates at a Chinese tertiary hospital over a 12-year period. Front Microbiol 2016;7:1714.

11. Biedenbach DJ, Bell JM, Sader HS, Fritsche TR, Jones RN, Turnidge JD. Antimicrobial susceptibility of gram-positive bacterial isolates from the Asia-Pacific Region and an in vitro evaluation of the bactericidal activity of daptomycin, vancomycin, and teicoplanin: A SENTRY program report (2003-2004). Int J Antimicrob Agents 2007;30:143-9.

12. Joshi S, Ray P, Manchanda V, Bajaj J, Chitnis DS, Gautam V, et al. Methicillin resistant Staphylococcus aureus (MRSA) in India: Prevalence and susceptibility pattern. Indian J Med Res 2013;137:363-9.

13. Diederen B, Duijn I, Willemse P, Jan A, Kluytmans J. In vitro activity of daptomycin against methicillin resistant Staphylococcus aureus, including heterogeneously glycopeptide-resistant strains. Antimicrob Agents Chemother 2006;50:3189-91.

14. Steinkraus G, White R, Friedrich L. Vancomycin MIC creep in non-vancomycin-intermediate Staphylococcus aureus (VISA), vancomycin-susceptible clinical methicillin-resistant S. aureus (MRSA) blood isolates from 2001-2005. J Antimicrob Chemother 2007;60:788-94.

15. Rai S, Niranjan DK, Kaur T, Singh NP, Hada V, Kaur IR, et al. Detection of the classical G2576U mutation in linezolid resistant Staphylococcus aureus along with isolation of linezolid resistant Enterococcus faecium from a patient on short-term linezolid therapy: First report from India. Indian J Med Microbiol 2015;33:21-4.

16. Chitnis S, Katara G, Hemvani N, Pareek S, Chitnis DS. In vitro activity of daptomycin and linezolid against methicillin resistant staphylococcus aureus \& vancomycin resistant enterococci isolated from hospitalized cases in central India. Indian J Med Res 2013;137:191-6. 